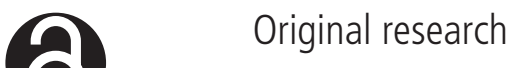

Occupational radiation exposure and cancer OPEN ACCESS \section{incidence in a cohort of diagnostic medical radiation workers in South Korea}

\author{
Won Jin Lee @ $1,{ }^{1}$ Seulki Ko, ${ }^{1}$ Ye Jin Bang, ${ }^{1}$ Seung-Ah Choe, ${ }^{1}$ Yeongchull Choi, ${ }^{2}$ \\ Dale L Preston ${ }^{3}$
}

- Additional supplemental material is published online only. To view, please visit the journal online (http://dx.doi. org/10.1136/oemed-2021 107452).

${ }^{1}$ Department of Preventive Medicine, Korea University College of Medicine, Seoul, South Korea

'Seoul Workers' Health Center, Ewha Womans University, Seoul, South Korea

${ }^{3}$ Hirosoft International, Eureka, California, USA

\section{Correspondence to}

DrWon Jin Lee, Department of Preventive Medicine, Korea University College of Medicine and School of Medicine, Seoul, South Korea; leewj@korea.ac.kr

Received 5 February 2021

Revised 22 April 2021

Accepted 3 May 2021
D) Check for updates

(C) Author(s) (or their employer(s)) 2021. Re-use permitted under CC BY-NC. No commercial re-use. See rights and permissions. Published by BMJ.

To cite: Lee WJ

Ko S, Bang YJ, et al.

Occup Environ Med Epub

ahead of print: [please include

Day Month Year]. doi:10.1136/

oemed-2021-107452

\section{ABSTRACT}

Objectives We investigated the association between protracted low-dose ionising radiation and the risk of cancer in medical radiation workers, the largest group of workers with occupational radiation exposures.

Methods Data of all South Korean diagnostic medical radiation workers enrolled at the National Dose Registry during 1996-2011 were merged with the death and cancer incidence data until 31 December 2017. SIRs, relative risks and excess relative risks (ERRs) for cancer were calculated to quantify the radiation dose-response relationship using Poisson regression models.

Results A total of 3392 first primary cancer cases were identified among 93920 diagnostic medical radiation workers. The mean cumulative badge dose in the cohort was $7.20 \mathrm{mSv}$. The ERRs for solid cancer with a 5-year lag and haematopoietic cancers with a 2-year lag for all workers were 0.15 per $100 \mathrm{mGy}(95 \% \mathrm{Cl}-0.20$ to $0.51)$ and 0.09 per $100 \mathrm{mGy}(95 \% \mathrm{Cl}-2.02$ to 2.20$)$, respectively. The ERRs for cancers did not significantly vary by job title, different lag years or after excluding thyroid and lung cancers. Sensitivity analyses restricted to workers employed for at least 1 year, or who were employed in or after 1996, or who had exposure to a cumulative badge dose of $1 \mathrm{mSv}$ or more showed similar results.

Conclusions Occupational radiation doses were not significantly associated with cancer incidence among South Korean diagnostic medical radiation workers. However, cautious interpretation of ERRs is needed due to the limitations of short follow-up and low cumulative radiation doses.

\section{INTRODUCTION}

Occupational radiation exposure studies provide an opportunity to directly investigate the health effects of external sources of ionising radiation. ${ }^{1}$ Medical radiation workers were among the first to be investigated for radiation-induced cancer risks and epidemiological studies of medical radiation workers have reported an increased risk of a few cancer sites. ${ }^{2}$ Medical radiation workers comprise more than half of all radiation workers exposed to man-made sources of radiation and a rapidly increasing professional group due to the expanding use of modern medical practices worldwide. ${ }^{3}$ These workers receive a protracted low level of radiation exposure, in which the nature of the exposure is qualitatively similar to that received by the general

\section{Key messages}

What is already known about this subject?

- A few studies have reported findings on health effects associated with protracted low-dose radiation exposures among medical radiation workers.

- However, the increased risks were mainly limited in the early period of workers who had prolonged exposure at high doses of radiation.

- There has been a rapid increase in the number of medical radiation workers with changes in their working environments, such as increasing implementation of new imaging techniques and radiation protection measures.

What are the new findings?

- Diagnostic medical radiation workers in South Korea showed differences in cancer incidence compared with the general population depending on sex and cancer site.

- Positive but not significant excess relative risks for cancer were observed, with similar results in study populations according to demographic and occupational characteristics.

How might this impact on policy or clinical practice in the foreseeable future?

- The findings contribute to a better knowledge of the health effects of low-dose chronic radiation exposures from a recently constructed cohort of medical radiation workers.

- More efforts to implement radiation protective measures should continue to minimise the potential health risks among medical radiation workers.

population, and are an identifiable professionally certified population, many of whom are women, with routinely obtained information on radiation exposure.

A few studies on medical radiation workers have reported important findings for direct observational evidence on health effects associated with chronic low-dose radiation exposures. ${ }^{245}$ However, the increased risks were mainly observed in the early period of exposure for prolonged exposures at doses higher than those currently reported and the studies do not include occupational exposure from 
new diagnostic imaging techniques. ${ }^{5}$ The average annual doses received by medical radiation workers have decreased dramatically, owing to technological advances in X-ray equipment and radiation protection measures to protect both patients and workers from the health effects of ionising radiation. Additionally, most studies ended the follow-up before the 2000s and have limited information on individual radiation organ doses and lifestyle factors.

In South Korea, medical radiation workers account for the majority of radiation workers (http://www.cdc.go.kr). We constructed a registry-based cohort by combining information on diagnostic medical radiation workers enrolled in the National Dose Registry (NDR) with national cancer incidence and mortality data in South Korea. Historical radiation dose reconstruction was performed and organ-specific radiation doses were estimated for the cohort. ${ }^{6}$ The findings of overall mortality, ${ }^{7}$ thyroid cancer incidence, ${ }^{8}$ circulatory disease morbidity, ${ }^{9}$ suicide death $^{10}$ and projected lifetime cancer risks ${ }^{11}$ were reported for this cohort. We have extended this study by linking the latest data on cancer incidence to investigate the role of occupational radiation exposure in cancer development among diagnostic medical radiation workers.

\section{METHODS}

\section{Study population}

The study population and methods have been described previously. ${ }^{78}$ Briefly, the study population comprised all diagnostic medical radiation workers enrolled in the NDR between 1 January 1996 and 31 December 2011 ( $n=94394)$. The cohort included radiological technologists, radiologists, physicians (non-radiologists), dentists, dental hygienists, nurses and others including medical assistants. Among workers whose data were registered in the database, those with any cancer before enrolment $(n=462)$ or those who had invalid NDR information $(n=12)$ were excluded. The analysis was therefore conducted on 93920 workers.

\section{Ascertainment of cancer incidence and vital status}

Cancer incidence was ascertained by linkage to the Korean Central Cancer Registry (KCCR), a centralised national registry of the Korean National Cancer Center, on request. Personal identification numbers were used for establishing a deterministic linkage. The KCCR provides the most completed and comprehensive data $(98.2 \%)^{12}$ regarding cancer codes, site, histological types, stage and date of diagnosis for all cancers identified in cohort members. Vital status was ascertained by Statistics Korea using a linkage method similar to the one used for the KCCR linkage. We followed up all diagnostic medical radiation workers for cancer incidence linkage with national cancer registry and national vital statistics until 31 December 2017.

\section{Definition of cancer outcomes}

We defined cancer cases as the first primary malignant tumours determined by the International Classification of Diseases and Related Health Problems, 10th Revision (ICD-10) code (C00C99). ${ }^{13}$ We selected cancer sites or groups based on a priori interests. First, we included individual organ sites for which there was sufficient evidence or positive association for the carcinogenicity of X-rays and gamma-radiation; medical radiation workers are often exposed to these types of ionising radiation, as revealed by an International Agency for Research on Cancer monograph. ${ }^{14}$ We limited the analysis to cancer sites with 30 or more cases. Since only two cases of chronic lymphocytic leukaemia (CLL) were observed in this cohort and an association has been reported between CLL and radiation exposure, ${ }^{15}$ we included CLL as a leukaemia category. Second, we considered a few groups of cancers, that is, all cancer combined, solid cancers and haematopoietic cancers defined by ICD-10 codes C00C99, C00-C81 and C81-C96, respectively. We included nonmelanoma skin cancer in the definition of all cancers because the KCCR has provided reliable nationwide incidence data of histologically confirmed non-melanoma skin cancers since $1999 .{ }^{16}$ Third, we considered solid cancers other than thyroid cancer cases owing to its high proportion of total cancers and potential overdiagnosis in South Korea. ${ }^{17}$ We additionally excluded lung cancer to indirectly minimise the potential effect of smoking because no individual data on lifestyle factors were available in this registry-linked cohort.

\section{Estimation of occupational characteristics and radiation dose} Occupational exposure data were obtained from the NDR database. The Korean Disease Control and Prevention Agency maintains the NDR system for all diagnostic medical radiation workers since 1996. Badge dose measurements, using a personal thermoluminescent dosimeter, were performed every quarter by five personnel monitoring centres. The standard practice in South Korea involved wearing the dosimeter under aprons on the left side at the level of the chest. The NDR database includes data on workers' name, sex, date of birth, personal identification number, workplace address, occupation, quarterly reported dose data, and the start date and the end date of the measurement period. Using the NDR information, the workers were categorised into seven groups according to job categories. Duration of employment was defined as the period between the beginning and the end of badge measurement for workers enrolled after 1996. For workers enrolled before or in 1996 (14.0\% of the total enrollees in the NDR), the start year of radiological practice for each sex and occupational group was imputed to be the mode of the age of job start from previous survey for diagnostic medical radiation workers. ${ }^{18}$

Radiation doses were estimated according to a previous method. ${ }^{6}$ Briefly, the annual and cumulative individual badge doses based on $H_{p}{ }^{10}$ were calculated by combining the quarterly badge readings of workers enrolled in the NDR. This effective dose (measured in Sievert) has the lowest detectable level of $0.01 \mathrm{mSv}$ per quarterly in the NDR. Historical badge doses were reconstructed for workers who began working with radiation before 1996 using an annual dose model that describes doses as a log-linear function of calendar year and age at the year of exposure. Colon and bone marrow absorbed doses (measured in Gray) were estimated by converting the individual badge dose to each organ-specific dose and multiplying these doses by two conversion coefficients provided by the International Commission on Radiological Protection. ${ }^{19} 20$ An anteroposterior irradiation geometry, which is most common in occupational exposure scenarios among medical radiation workers, was assumed. The dominant energy of the diagnostic radiation fields was assumed to be between $30 \mathrm{keV}$ and $40 \mathrm{keV}^{21}{ }^{22}$ The equation was $H_{p}(d)\left[\frac{D_{T}}{K_{a}} / \frac{H_{p}(d)}{K_{a}}\right]$, where $H_{p}(d)$ is the equivalent dose; $\frac{D_{T}}{K_{a}}$ is the air kerma-to-organ dose conversion coefficient and $\frac{H_{p}(d)}{K_{a}}$ is the air kerma-to-personal dose equivalent conversion coefficient. The organ absorbed doses were adjusted for the probability of apron use and badge placement, which were obtained from a nationwide survey for diagnostic medical radiation workers. ${ }^{18}$ The equation for the estimation of organ 
Table 1 Occupational characteristics by sex in South Korean diagnostic medical radiation workers

\begin{tabular}{|c|c|c|c|c|}
\hline \multirow[b]{2}{*}{ Characteristics } & \multicolumn{2}{|l|}{ Male } & \multicolumn{2}{|l|}{ Female } \\
\hline & Number & $\%$ & Number & $\%$ \\
\hline Total & 53582 & 100.0 & 40338 & 100.0 \\
\hline \multicolumn{5}{|l|}{ Occupation } \\
\hline Radiological technologist & 17222 & 32.1 & 9021 & 22.4 \\
\hline Radiologist & 1190 & 2.2 & 541 & 1.3 \\
\hline Dentist & 12178 & 22.7 & 3381 & 8.4 \\
\hline Dental hygienist & 75 & 0.1 & 13404 & 33.2 \\
\hline Nurse & 422 & 0.8 & 7103 & 17.6 \\
\hline Other physician & 15780 & 29.4 & 2611 & 6.4 \\
\hline Others & 6715 & 12.5 & 4277 & 10.6 \\
\hline \multicolumn{5}{|l|}{ Type of facility } \\
\hline General hospital & 11254 & 21.0 & 9871 & 24.5 \\
\hline Hospital and clinic & 26390 & 42.3 & 10197 & 25.3 \\
\hline Dental hospital and clinic & 12415 & 23.2 & 19356 & 47.9 \\
\hline Others & 3523 & 6.6 & 914 & 2.3 \\
\hline \multicolumn{5}{|l|}{ Area of facility } \\
\hline Metropolitan & 26534 & 49.5 & 23533 & 58.3 \\
\hline City & 22550 & 42.1 & 15436 & 38.3 \\
\hline Rural & 4498 & 8.4 & 1369 & 3.4 \\
\hline \multicolumn{5}{|l|}{ Calendar year of birth } \\
\hline$<1960$ & 9623 & 18.0 & 865 & 2.1 \\
\hline 1960-1969 & 18768 & 35.0 & 5576 & 13.8 \\
\hline 1970-1979 & 17039 & 31.8 & 15856 & 39.3 \\
\hline$\geq 1980$ & 8152 & 15.2 & 18041 & 44.7 \\
\hline \multicolumn{5}{|l|}{ Age at entry (years) } \\
\hline$<25$ & 10904 & 20.3 & 19483 & 48.3 \\
\hline $25-30$ & 14726 & 27.5 & 11231 & 27.8 \\
\hline $30-35$ & 9090 & 17.0 & 4833 & 12.0 \\
\hline $35-40$ & 8678 & 16.2 & 2800 & 6.9 \\
\hline$\geq 40$ & 10184 & 19.0 & 1991 & 4.9 \\
\hline \multicolumn{5}{|l|}{ Calendar year of work began } \\
\hline$<1996$ & 9817 & 18.3 & 3327 & 8.3 \\
\hline 1996-2004 & 21718 & 40.5 & 13405 & 33.2 \\
\hline$\geq 2005$ & 22047 & 41.2 & 23606 & 58.5 \\
\hline \multicolumn{5}{|l|}{ Duration of employment (years) } \\
\hline$<1$ & 7427 & 13.9 & 10708 & 26.5 \\
\hline $1-5$ & 15692 & 29.3 & 17333 & 43.0 \\
\hline $5-10$ & 14012 & 26.2 & 8092 & 20.1 \\
\hline$\geq 10$ & 16451 & 30.7 & 4205 & 10.4 \\
\hline \multicolumn{5}{|l|}{ Cumulative badge dose (mSv) } \\
\hline$<1$ & 22021 & 41.1 & 26037 & 64.5 \\
\hline $1-5$ & 12386 & 23.1 & 8877 & 22.0 \\
\hline $5-20$ & 10504 & 19.6 & 4461 & 11.1 \\
\hline$\geq 20$ & 8671 & 16.2 & 963 & 2.4 \\
\hline
\end{tabular}

doses was $D_{o}=D_{c} \times R_{\text {coef }} \times\left(P_{N o A}+A A \times P_{A O}+P_{A U}\right)$, where $D_{o}$ is the organ dose, $D_{c}$ is the personal cumulative badge dose, $R_{c o e f}$ is the conversion coefficient, $P_{\text {NoA }}$ is the probability of not wearing apron at work, $P_{A O}$ is the probability of wearing the badge outside the apron, $P_{A U}$ is the probability of wearing the badge inside the apron, and $A A$ is the apron attenuation factor. We assumed an attenuation rate of 0.8 for the use of lead aprons to reflect the shielding effect, based on previous studies. ${ }^{11} 21$

\section{Statistical analyses}

Each person contributed person-years at risk from 1996 or from the year of the start of work based on the NDR, whichever occurred later. The end of follow-up was taken as the earliest of the following: date of any malignant cancer diagnosis, date of death or 31 December 2017. The DATAB module in Epicure software was used to create a person-year table stratified by sex, attained age $(<25,5$-year intervals from the age of $25-84, \geq 85$ years), calendar year (1996-2000, 2001-2005, 2006-2010, 2011-2017), birth year $(<1960,1960-1969,1970-1979$, $\geq 1980)$, year of job entry $(<2000,2000-2004, \geq 2005)$, job titles (seven categories, as described above), year first worked $(<1996,1996-2004, \geq 2005)$, age at first job $(<25,25-30$, $30-35,35-40, \geq 40)$, years of employment duration $(<1,1-5$, $5-10, \geq 10$ ), type of medical facility (general hospital, hospital and clinic, dental hospital and clinic, others), area of medical facility (metropolitan, city, rural) and cumulative badge dose $(<1,1-5,5-20, \geq 20 \mathrm{mSv})$.

Crude cancer rates per 100000 by cancer groups and individual organ sites were calculated by dividing the number of cancers by the person-years in the corresponding groups. SIRs and the corresponding 95\% CIs for all cancers and site-specific cancers were calculated using the South Korean cancer incidence rates using Poisson-regression methods. The expected number of incident cancers for each cell was computed as the product of the number of person-years and the sex-specific, age-specific and calendar-year-specific South Korean cancer incidence rates (http://www.ncc.re.kr/). Reference rates were limited to the follow-up period 1999-2017 because nationwide cancer incidence rates were available only from 1999 in South Korea. For the period 1996-1998, we assumed that the cancer incidence rates were the same as those in 1999. Relative risks (RRs) and corresponding 95\% CIs were calculated by Poisson regression using the maximum likelihood method. The linear trends of RRs with cumulative badge dose categories was examined by using simple dose-response models.

Excess relative risks (ERRs) and 95\% CIs for cancer incidence were calculated using Poisson regression to analyse the relationship between cumulative organ doses and cancer incidence. The primary model used to evaluate the dose-response assumes a linear dose-response relationship as classically used in radiation epidemiology. ${ }^{23}$ The linear model can be written as $R R=1+\beta d$, where $R R$ is the relative risk, $d$ is the dose and $\beta$ is an estimate of the ERR per unit dose (ERR/100 mSv). Parameter estimates and $95 \%$ confidence bounds were calculated using the maximum likelihood method. The variables were selected based on the deviance and Akaike information criterion of each model. The final models were adjusted for attained age, sex, birth year and duration of employment in a person-year table stratified by the factors described above. The duration of employment was considered a priori to control for negative confounding due to the healthy worker effect, as has been noted previously in this cohort. ${ }^{7810}$ All analyses were conducted using the AMFIT module in Epicure.

Sensitivity analyses for ERRs were conducted on workers employed for at least 1 year $(n=75785)$ to avoid possible heterogeneity of the subjects, on those who started work after 1995 $(\mathrm{n}=80776)$ to reduce the uncertainties for dose reconstruction, or on those who had cumulative badge dose exposure of $1 \mathrm{mSv}$ or more $(n=45862)$ to focus on more exposed workers. We also examined variations in baseline rates and radiation risks by job title (physicians and non-physicians) and sex. To allow for the practical latent period of radiation effect in this cohort, 
Table 2 Crude rate per 100000 and SIRs of cancer sites by sex in South Korean diagnostic medical radiation workers, 1996-2017

\begin{tabular}{|c|c|c|c|c|c|c|}
\hline \multirow[b]{2}{*}{$\begin{array}{l}\text { Cancer sites } \\
\text { (ICD-10 code) }\end{array}$} & \multicolumn{3}{|l|}{ Male } & \multicolumn{3}{|l|}{ Female } \\
\hline & Observed cases & Crude rate & $\begin{array}{l}\text { SIR } \\
(95 \% \mathrm{Cl}) \\
\end{array}$ & Observed cases & Crude rate & $\begin{array}{l}\text { SIR } \\
(95 \% \mathrm{Cl}) \\
\end{array}$ \\
\hline $\begin{array}{l}\text { All cancers combined } \\
\text { (C00-C96) }\end{array}$ & 2093 & 270.0 & 0.90 (0.86 to 0.94$)$ & 1299 & 256.8 & $1.11(1.05$ to 1.17$)$ \\
\hline $\begin{array}{l}\text { Solid cancers } \\
\text { (C00-C81) }\end{array}$ & 1948 & 251.3 & 0.88 (0.84 to 0.92$)$ & 1272 & 251.5 & 1.11 (1.06 to 1.18$)$ \\
\hline Solid cancers other than thyroid & 1593 & 205.5 & 0.79 (0.76 to 0.83$)$ & 641 & 126.7 & 1.01 (0.93 to 1.09$)$ \\
\hline Solid cancers other than thyroid and lung & 1461 & 188.5 & 0.83 (0.79 to 0.88$)$ & 614 & 121.4 & 1.00 (0.92 to 1.08$)$ \\
\hline All-haematopoietic cancers (C81-C96) & 145 & 18.7 & 1.30 (1.10 to 1.53$)$ & 27 & 5.34 & 0.82 (0.56 to 1.20$)$ \\
\hline Stomach (C16) & 308 & 39.7 & 0.67 (0.60 to 0.75$)$ & 58 & 11.5 & 0.81 (0.63 to 1.05 ) \\
\hline Colorectal (C18-C20) & 311 & 40.1 & 0.95 (0.85 to 1.06$)$ & 40 & 7.91 & 0.77 (0.56 to 1.05$)$ \\
\hline Liver (C22) & 185 & 23.9 & 0.58 (0.50 to 0.67 ) & 9 & 1.78 & 0.60 (0.31 to 1.16$)$ \\
\hline Pancreas (C25) & 54 & 6.97 & 0.98 (0.75 to 1.28$)$ & 7 & 1.38 & 1.09 (0.52 to 2.28$)$ \\
\hline Lung (C33-C34) & 132 & 17.0 & 0.52 (0.44 to 0.62$)$ & 27 & 5.34 & 1.21 (0.83 to 1.76$)$ \\
\hline Non-melanoma skin (C44) & 34 & 4.39 & 1.06 (0.76 to 1.48$)$ & 4 & 0.79 & 0.57 (0.21 to 1.52$)$ \\
\hline Female breast (C50) & - & - & - & 326 & 64.5 & 1.25 (1.12 to 1.39$)$ \\
\hline Prostate (C61) & 156 & 20.1 & 1.44 (1.23 to 1.69$)$ & - & - & - \\
\hline Kidney (C64) & 112 & 14.5 & 1.50 (1.25 to 1.81$)$ & 10 & 0.98 & 0.99 (0.54 to 1.85$)$ \\
\hline Bladder (C67) & 60 & 7.74 & 1.13 (0.87 to 1.45$)$ & 2 & 0.40 & 0.87 (0.22 to 3.49 ) \\
\hline Brain and CNS (C70-72) & 27 & 3.48 & 1.04 (0.72 to 1.52$)$ & 16 & 3.16 & 1.61 (0.98 to 2.62 ) \\
\hline Thyroid (C73) & 355 & 45.8 & 1.74 (1.57 to 1.93$)$ & 631 & 124.8 & 1.25 (1.16 to 1.36$)$ \\
\hline NHL (C82-C85, C96) & 49 & 6.32 & 0.92 (0.69 to 1.21$)$ & 12 & 2.37 & 0.82 (0.47 to 1.45 ) \\
\hline Leukaemia (C91-C95) & 51 & 6.58 & 1.25 (0.95 to 1.65$)$ & 7 & 1.38 & 0.48 (0.23 to 1.01$)$ \\
\hline
\end{tabular}

CNS, central nervous system; ICD-10, International Classification of Diseases and Related Health Problems, 10th Revision; NHL, non-Hodgkin's lymphoma.

cumulative colon dose had a lag of 5 years for solid cancers and cumulative bone marrow dose had a lag of 2 years for haematopoietic cancers. We also considered alternative lagged cumulative organ doses (ie, 10 years for solid cancer and 5 years for haematopoietic cancers).

\section{RESULTS}

Among the 93920 cohort members (53582 men and 40338 women), radiological technologists formed the largest group of workers, followed by doctors and dentists (table 1). The majority of the workers were born after 1960, and more than $70 \%$ of workers started work after 2004. The mean attained age at the end of follow-up was 41.2 years for men and 35.2 years for women with a mean follow-up of 13.6 years per worker. Average mean cumulative doses of the badge were $7.2 \mathrm{mSv}$ (IQR $0.21-5.41 \mathrm{mSv}$ ) and the distribution of doses was skewed, with $51 \%$ of the entire workers having cumulative badge doses lower than $1 \mathrm{mSv}$.

A total of 3392 first primary cancer cases (2093 cases in male and 1299 cases in female workers) were ascertained between 1996 and 2017 (table 2). Male diagnostic medical radiation workers experienced significantly lower risks of solid cancer than the general South Korean population (SIR 0.88, 95\% CI 0.84 to 0.92 ); in contrast, the risks for female workers were significantly elevated (SIR $1.11,95 \%$ CI 1.06 to 1.18 ). The exclusion of thyroid cancers or additional exclusion of lung cancer did not result in significant changes in SIRs in both sexes. There were notable differences in SIRs of a few site-specific cancers.

Table 3 presents the baseline SIRs and RRs of categorical analyses by cumulative badge doses. The point estimates of baseline SIRs for all cancer sites were similar with those of overall SIRs in table 2. The RRs of the highest dose category for solid and haematopoietic cancers were 0.94 (95\% CI 0.85 to 1.04) and 0.99 (95\% CI 0.65 to 1.50 ) compared with the lowest dose category, respectively. There was no significant trend in the individual cancer risks with radiation dose categories.

The ERRs for solid cancers and haematopoietic cancers for all workers were 0.15 per $100 \mathrm{mGy}(95 \% \mathrm{CI}-0.20$ to 0.51$)$ and 0.09 per $100 \mathrm{mGy}(95 \% \mathrm{CI}-2.02$ to 2.20$)$, respectively (table 4). Exclusion of thyroid cancer yielded a slightly higher ERR point estimate than solid cancer risk. None of the ERRs for individual cancer sites showed meaningfully significant findings. Similar risk estimates were seen when the analyses were restricted to workers employed for at least 1 year or who started work after 1995 or who had cumulative badge dose exposure of $1 \mathrm{mSv}$ or more. Similar patterns were seen when using alternative lagged doses (online supplemental table 1). Analyses without adjustment for employment duration showed lower ERR estimates, however, the findings were not significantly different from those adjusted for employment duration (online supplemental table 2).

\section{DISCUSSION}

Our findings revealed that occupational radiation exposure was not significantly associated with cancer incidence among diagnostic medical radiation workers in South Korea during 19962017. The findings of positive but not significant ERRs for cancers were similar between study populations and alternative lag-years. Given the relatively young age of the cohort members, short follow-up period, and increasing use of radiation in modern medical practices, it is important to investigate the risk of cancer in medical radiation workers exposed to chronic lowdose radiation by conducting a study with extended follow-up together with consideration of other risk factors.

Our ERR findings were generally comparable to those seen in other epidemiological studies from low-dose radiation workers. ${ }^{24}$ The non-significant findings of dose-response relationships between occupational radiation exposure and cancer incidence may be related with our cohort characteristics. First, 
Table 3 Baseline SIRs and RRs of cancer incidence by radiation dose in South Korean diagnostic medical radiation workers, 1996-2017

\begin{tabular}{|c|c|c|c|c|c|c|}
\hline \multirow{2}{*}{$\begin{array}{l}\text { Cancer sites } \\
\text { (ICD-10 code) }\end{array}$} & \multirow[b]{2}{*}{ Baseline SIRs $(95 \% \mathrm{Cl})^{*}$} & \multicolumn{4}{|c|}{ RRs $(95 \% \mathrm{Cl})$ by cumulative badge dose categories (mSv) } & \multirow[b]{2}{*}{$P$ trend } \\
\hline & & $<1$ & $1-5$ & $5-20$ & $\geq 20$ & \\
\hline All cancers combined (C00-C96) & $1.00(0.95$ to 1.05$)$ & 1.0 (ref) & $0.96(0.88$ to 1.05$)$ & $0.97(0.88$ to 1.06$)$ & 0.94 (0.86 to 1.04$)$ & 0.753 \\
\hline Cases & & 1382 & 776 & 620 & 614 & \\
\hline Solid cancers (C00-C81) & 0.99 (0.94 to 1.05$)$ & 1.0 (ref) & 0.95 (0.87 to 1.04$)$ & 0.97 (0.88 to 1.06$)$ & 0.94 (0.85 to 1.04$)$ & 0.779 \\
\hline Cases & & 1317 & 734 & 588 & 581 & \\
\hline Solid cancers other than thyroid & $0.88(0.83$ to 0.95$)$ & 1.0 (ref) & 0.89 (0.79 to 0.99$)$ & 0.91 (0.81 to 1.03$)$ & 0.99 (0.89 to 1.11$)$ & 0.511 \\
\hline Cases & & 850 & 474 & 406 & 504 & \\
\hline Solid cancers other than thyroid and lung & 0.91 (0.85 to 0.97 ) & 1.0 (ref) & $0.89(0.79$ to 1.00$)$ & $0.93(0.82$ to 1.05$)$ & $1.02(0.91$ to 1.14$)$ & 0.537 \\
\hline Cases & & 794 & 443 & 382 & 456 & \\
\hline All-haematopoietic cancers (C81-C96) & $1.20(0.94$ to 1.53$)$ & 1.0 (ref) & 1.04 (0.70 to 1.53$)$ & 0.94 (0.62 to 1.44$)$ & $0.99(0.65$ to 1.50$)$ & 0.788 \\
\hline Cases & & 65 & 42 & 32 & 33 & \\
\hline Stomach (C16) & 0.71 (0.59 to 0.84 ) & 1.0 (ref) & 1.03 (0.78 to 1.35$)$ & 0.94 (0.70 to 1.26$)$ & 0.93 (0.70 to 1.23 ) & 0.288 \\
\hline Cases & & 125 & 88 & 70 & 83 & \\
\hline Colorectal (C18-C20) & $0.98(0.83$ to 1.17$)$ & 1.0 (ref) & $0.85(0.64$ to 1.13$)$ & 0.85 (0.63 to 1.15$)$ & 1.01 (0.77 to 1.33$)$ & 0.482 \\
\hline Cases & & 130 & 73 & 62 & 86 & \\
\hline Liver (C22) & 0.54 (0.42 to 0.71$)$ & 1.0 (ref) & 0.92 (0.61 to 1.38 ) & 0.95 (0.63 to 1.45$)$ & 1.38 (0.96 to 1.97$)$ & 0.484 \\
\hline Cases & & 56 & 39 & 36 & 63 & \\
\hline Pancreas (C25) & 1.32 (0.90 to 1.92 ) & 1.0 (ref) & 0.57 (0.27 to 1.17$)$ & 0.64 (0.31 to 1.32 ) & 0.67 (0.35 to 1.27$)$ & 0.795 \\
\hline Cases & & 27 & 10 & 10 & 14 & \\
\hline Lung (C33-C34) & 0.64 (0.49 to 0.83 ) & 1.0 (ref) & 0.87 (0.56 to 1.36$)$ & 0.73 (0.46 to 1.19 ) & 0.92 (0.63 to 1.36 ) & 0.518 \\
\hline Cases & & 56 & 31 & 24 & 48 & \\
\hline Non-melanoma skin (C44) & 0.69 (0.37 to 1.28$)$ & 1.0 (ref) & $1.66(0.69$ to 4.00$)$ & 1.79 (0.73 to 4.41$)$ & $1.49(0.61$ to 3.67$)$ & 0.785 \\
\hline Cases & & 10 & 10 & 9 & 9 & \\
\hline Female breast (C50) & 1.11 (0.95 to 1.30$)$ & 1.0 (ref) & 1.00 (0.75 to 1.34 ) & 1.00 (0.71 to 1.41$)$ & 1.01 (0.53 to 1.91 ) & 0.799 \\
\hline Cases & & 155 & 98 & 53 & 20 & \\
\hline Prostate (C61) & 1.76 (1.37 to 2.25$)$ & 1.0 (ref) & 0.61 (0.38 to 1.00$)$ & 0.56 (0.33 to 0.93$)$ & 0.92 (0.64 to 1.32 ) & 0.756 \\
\hline Cases & & 62 & 22 & 19 & 53 & \\
\hline Kidney (C64) & 1.57 (1.19 to 2.09 ) & 1.0 (ref) & 0.70 (0.42 to 1.16$)$ & 1.02 (0.64 to 1.64 ) & 0.92 (0.57 to 1.50$)$ & 0.425 \\
\hline Cases & & 48 & 22 & 27 & 25 & \\
\hline Bladder (C67) & 0.98 (0.61 to 1.57 ) & 1.0 (ref) & 0.71 (0.31 to 1.64 ) & 1.84 (0.96 to 3.54$)$ & 1.15 (0.59 to 2.23 ) & 0.535 \\
\hline Cases & & 17 & 8 & 19 & 18 & \\
\hline Brain and CNS (C70-72) & 1.45 (0.94 to 2.24 ) & 1.0 (ref) & 0.48 (0.19 to 1.20$)$ & 1.07 (0.51 to 2.24$)$ & 0.66 (0.26 to 1.63$)$ & 0.860 \\
\hline Cases & & 20 & 6 & 11 & 6 & \\
\hline Thyroid (C73) & 1.26 (1.15 to 1.38$)$ & 1.0 (ref) & 1.18 (1.01 to 1.37 ) & 1.29 (1.09 to 1.53$)$ & 1.18 (0.93 to 1.50$)$ & 0.990 \\
\hline Cases & & 467 & 260 & 182 & 77 & \\
\hline NHL (C82-C85, C96) & 0.79 (0.51 to 1.22 ) & 1.0 (ref) & 1.27 (0.66 to 2.46 ) & 1.14 (0.56 to 2.34 ) & 1.24 (0.61 to 2.48 ) & 0.953 \\
\hline Cases & & 20 & 16 & 12 & 13 & \\
\hline Leukaemia (C91-C95) & 1.23 (0.83 to 1.80$)$ & 1.0 (ref) & 1.00 (0.54 to 1.86$)$ & 0.37 (0.14 to 0.97 ) & 0.90 (0.44 to 1.81$)$ & 0.863 \\
\hline Cases & & 26 & 16 & 5 & 11 & \\
\hline
\end{tabular}

${ }^{*}$ SIR for the $<1 \mathrm{mSv}$ dose category.

CNS, central nervous system; ICD-10, International Classification of Diseases and Related Health Problems, 10th Revision; NHL, non-Hodgkin's lymphoma; RR, relative risk.

the large proportion of young workers of our cohort started jobs after the 1990s. This leads to short follow-up and yields a lower cumulative radiation dose than that in other cohorts. Previous positive findings with radiation exposure among medical radiation workers were mainly limited to early period workers who have prolonged exposure at higher doses than those currently reported. ${ }^{5}$ In the US Radiologic Technologists (USRT) study, the increased cancer risk was mainly observed in workers who joined before the 1950 s. $^{2}$ In a Chinese study, the RRs of leukaemia and solid cancer were significantly high in the earlier cohort but not in the later cohort and their mean radiation badge dose was $0.25 \mathrm{~Gy}^{22}$ The relatively young age of this cohort and the short follow-up period may have underpowered the detection of radiation-induced cancers. However, Canadian radiation workers had similar radiation doses $(6.64 \mathrm{mSv}$ mean cumulative dose) and follow-up periods (ie, 14 years) as those of our cohort but showed significantly increased ERR for a few cancer sites. ${ }^{25}$ Therefore, it is worth investigating the radiation effects in different work practices or populations as well as perform further follow-up until the majority of cohort members' attained age reached at the age of the highest risk of cancer occurrence.

The low proportion of high-radiation exposure jobs in our cohort would also be a possible reason for the statistically not significant findings. The proportion of interventional medical workers who perform fluoroscopically guided procedures was assumed to be about 7\% among the total diagnostic medical radiation workers in South Korea. ${ }^{18}$ Our registry also did not include medical workers involved in nuclear medicine and therapeutic departments, while previous positive findings appear more for workers who performed fluoroscopically guided interventional procedures or worked in radionuclide procedures. ${ }^{5}$ In the USRT, increased risks of breast cancer from occupational 
Table 4 ERRs per $100 \mathrm{mGy}$ for cancer incidence by cumulative organ doses by study populations in South Korean diagnostic medical radiation workers, 1996-2017

\begin{tabular}{|c|c|c|c|c|}
\hline $\begin{array}{l}\text { Cancer sites } \\
\text { (ICD-10 code) }\end{array}$ & $\begin{array}{l}\text { All workers } \\
(n=93920)\end{array}$ & $\begin{array}{l}\text { Worker employed } \\
\geq 1 \text { years } \\
(n=75785)\end{array}$ & $\begin{array}{l}\text { Workers started job } \\
\geq 1996 \\
(\mathrm{n}=80776)\end{array}$ & $\begin{array}{l}\text { Workers had } \\
\geq 1 \mathrm{mSv} \\
(\mathrm{n}=45862)\end{array}$ \\
\hline \multicolumn{5}{|c|}{ All cancers combined (C00-C96) } \\
\hline Cases & 3392 & 2962 & 2391 & 2010 \\
\hline $\operatorname{ERR}(95 \% \mathrm{Cl})^{*}$ & $0.15(-0.20$ to 0.50$)$ & $0.15(-0.20$ to 0.51$)$ & $0.93(-0.60$ to 2.46$)$ & $0.20(-0.18$ to 0.57$)$ \\
\hline \multicolumn{5}{|c|}{ Solid cancers (C00-C81) } \\
\hline Cases & 3220 & 2813 & 2268 & 1903 \\
\hline $\operatorname{ERR}(95 \% \mathrm{Cl})$ & $0.15(-0.20$ to 0.51$)$ & $0.17(-0.20$ to 0.53$)$ & $0.79(-0.77$ to 2.35$)$ & $0.21(-0.18$ to 0.60$)$ \\
\hline \multicolumn{5}{|c|}{ Solid cancers other than thyroid } \\
\hline Cases & 2234 & 1992 & 1456 & 1384 \\
\hline $\operatorname{ERR}(95 \% \mathrm{Cl})$ & $0.24(-0.15$ to 0.64$)$ & $0.26(-0.15$ to 0.66$)$ & $0.92(-1.05$ to 2.90$)$ & $0.35(-0.10$ to 0.79$)$ \\
\hline \multicolumn{5}{|c|}{ Solid cancers other than thyroid and lung } \\
\hline Cases & 2075 & 1845 & 1360 & 1281 \\
\hline $\operatorname{ERR}(95 \% \mathrm{Cl})$ & $0.17(-0.24$ to 0.57$)$ & $0.18(-0.23$ to 0.59$)$ & $0.96(-1.08$ to 3.00$)$ & $0.22(-0.21$ to 0.66$)$ \\
\hline \multicolumn{5}{|c|}{ All-haematopoietic cancers (C81-C96) } \\
\hline Cases & 172 & 149 & 123 & 107 \\
\hline ERR $(95 \% \mathrm{Cl})$ & $0.09(-2.02$ to 2.20$)$ & $-0.12(-2.02$ to 1.99$)$ & $3.80(-5.24$ to 12.9$)$ & $0.03(-2.09$ to 2.15$)$ \\
\hline \multicolumn{5}{|l|}{ Stomach (C16) } \\
\hline Cases & 366 & 332 & 229 & 241 \\
\hline $\operatorname{ERR}(95 \% \mathrm{Cl})$ & $-0.38(-0.80$ to 0.04$)$ & $-0.38(-0.77$ to 0.01$)$ & $-0.40(-2.36$ to 1.56$)$ & $-0.38(-1.05$ to 0.30$)$ \\
\hline \multicolumn{5}{|c|}{ Colorectal (C18-C20) } \\
\hline Cases & 351 & 317 & 228 & 221 \\
\hline $\operatorname{ERR}(95 \% \mathrm{Cl})$ & $0.38(-0.67$ to 1.43$)$ & $0.39(-0.68$ to 1.46$)$ & $-0.38(-3.83$ to 3.07$)$ & $0.34(-0.73$ to 1.42$)$ \\
\hline \multicolumn{5}{|l|}{ Liver (C22) } \\
\hline Cases & 194 & 184 & 112 & 138 \\
\hline ERR $(95 \% \mathrm{Cl})$ & $1.39(-0.55$ to 3.33$)$ & $1.37(-0.57$ to 3.31$)$ & $-0.35(-5.13$ to 4.43$)$ & $1.34(-0.67$ to 3.35$)$ \\
\hline \multicolumn{5}{|l|}{ Pancreas (C25) } \\
\hline Cases & 61 & 51 & 40 & 34 \\
\hline ERR $(95 \% \mathrm{Cl})$ & $-0.38(-1.75$ to 1.00$)$ & $-0.38(-1.78$ to 1.02$)$ & $-0.36(-9.10$ to 8.38$)$ & $-0.13(-2.21$ to 1.94$)$ \\
\hline \multicolumn{5}{|l|}{ Lung (C33-C34) } \\
\hline Cases & 159 & 147 & 96 & 103 \\
\hline ERR $(95 \% \mathrm{Cl})$ & 1.15 (-0.71 to 3.02$)$ & $1.21(-0.71$ to 3.12$)$ & $0.45(-7.14$ to 8.05$)$ & $2.25(-0.60$ to 5.09$)$ \\
\hline \multicolumn{5}{|c|}{ Non-melanoma skin (C44) } \\
\hline Cases & 38 & 34 & 27 & 28 \\
\hline ERR $(95 \% \mathrm{Cl})$ & $-0.38(-2.17$ to 1.41$)$ & $-0.37(-2.59$ to 1.84$)$ & $21.4(-15.8$ to 58.5$)$ & $-0.37(-2.65$ to 1.91$)$ \\
\hline \multicolumn{5}{|c|}{ Female breast (C50) } \\
\hline Cases & 326 & 270 & 245 & 171 \\
\hline ERR $(95 \% \mathrm{Cl})$ & $-0.38(-0.68$ to -0.08$)$ & $-0.37(-1.11$ to 0.37$)$ & -1.12 (-4.78 to 2.54$)$ & $-0.33(-1.55$ to 0.89$)$ \\
\hline \multicolumn{5}{|l|}{ Prostate (C61) } \\
\hline Cases & 156 & 135 & 91 & 94 \\
\hline $\operatorname{ERR}(95 \% \mathrm{Cl})$ & $-0.25(-1.01$ to 0.51$)$ & $-0.27(-1.01$ to 0.48$)$ & $5.47(-8.56$ to 19.5$)$ & $-0.25(-1.02$ to 0.51$)$ \\
\hline \multicolumn{5}{|l|}{ Kidney (C64) } \\
\hline Cases & 122 & 108 & 82 & 74 \\
\hline ERR $(95 \% \mathrm{Cl})$ & $-0.26(-1.74$ to 1.23$)$ & $-0.35(-1.71$ to 1.01$)$ & $2.91(-6.22$ to 12.0$)$ & $-0.24(-1.77$ to 1.30$)$ \\
\hline \multicolumn{5}{|l|}{ Bladder (C67) } \\
\hline Cases & 62 & 53 & 34 & 45 \\
\hline ERR $(95 \% \mathrm{Cl})$ & $0.64(-1.62$ to 2.90$)$ & $0.61(-1.65$ to 2.87$)$ & $11.4(-16.2$ to 39.1$)$ & $0.62(-1.70$ to 2.93$)$ \\
\hline \multicolumn{5}{|c|}{ Brain and CNS (C70-72) } \\
\hline Cases & 43 & 39 & 30 & 23 \\
\hline ERR $(95 \% \mathrm{Cl})$ & $-0.29(-3.14$ to 2.55$)$ & $-0.30(-3.08$ to 2.48$)$ & $-0.37(-10.6$ to 9.82$)$ & -0.31 ( -2.96 to 2.34$)$ \\
\hline \multicolumn{5}{|l|}{ Thyroid (C73) } \\
\hline Cases & 986 & 821 & 812 & 519 \\
\hline ERR $(95 \% \mathrm{Cl})$ & $-0.31(-1.24$ to 0.62$)$ & $-0.29(-1.27$ to 0.70$)$ & $0.76(-1.87$ to 3.40$)$ & $-0.32(-1.25$ to 0.60$)$ \\
\hline \multicolumn{5}{|c|}{ NHL (C82-C85, C96) } \\
\hline Cases & 61 & 55 & 42 & 41 \\
\hline ERR $(95 \% \mathrm{Cl})$ & -0.41 ( -2.88 to 2.07$)$ & $-0.55(-2.08$ to 0.99$)$ & $7.16(-11.7$ to 26.0$)$ & $-0.55(-2.08$ to 0.99$)$ \\
\hline
\end{tabular}


Table 4 continued

\begin{tabular}{lllll}
\hline $\begin{array}{l}\text { Cancer sites } \\
\text { (ICD-10 code) }\end{array}$ & $\begin{array}{l}\text { All workers } \\
(\mathbf{n}=93920)\end{array}$ & $\begin{array}{l}\text { Worker employed } \\
\geq 1 \text { years } \\
(\mathbf{n}=75785)\end{array}$ & $\begin{array}{l}\text { Workers started job } \\
\geq 1996 \\
(\mathbf{n}=80776)\end{array}$ & $\begin{array}{l}\text { Workers had } \\
\geq 1 \text { mSv } \\
(\mathbf{n}=45862)\end{array}$ \\
\hline $\begin{array}{l}\text { Leukaemia }(\mathrm{C} 91-\mathrm{C} 95) \\
\quad \text { Cases }\end{array}$ & 58 & 49 & 45 & 32 \\
$\quad$ ERR $(95 \% \mathrm{Cl})$ & $-0.54(-3.54$ to 2.45$)$ & $-0.55(-1.49$ to 0.39$)$ & $2.13(-11.9$ to 16.2$)$ & $-0.50(-3.98$ to 2.98$)$ \\
\hline
\end{tabular}

${ }^{*}$ Adjusted for attained age $(<25,5$-year intervals from the age of $25-84, \geq 85$ years), sex, birth year (<1960, 1960-1969, 1970-1979, $\geq 1980)$ and years of employment duration $(<1,1-5,5-10, \geq 10)$.

CNS, central nervous system; ERR, excess relative risk; ICD-10, International Classification of Diseases and Related Health Problems, 10th Revision; NHL, non-Hodgkin's lymphoma.

radiation exposure have been reported for radiological technologists exposed to fluoroscopically guided procedures ${ }^{26}$ or nuclear medicine procedures. ${ }^{27}$ US physicians who are likely to perform fluoroscopically guided interventional procedures ${ }^{28}$ or radiologists $^{29}$ had decreased cancer mortality compared with psychiatrists, but an increased risk of leukaemia mortality was observed among male physicians who graduated from medical school before 1940. More focused studies targeting medical radiation workers who receive high doses, or workers who perform radiation interventional procedures, are warranted. ${ }^{30}$

Our findings may also relate to non-occupational radiation factors that were not ascertained in this study, such as medical radiation exposure or lifestyle factors. These possible confounding factors may have a substantial effect on risk estimates, especially when conducting studies of low-level radiation. ${ }^{23}$ The increased SIRs at a few cancer sites but no significant ERRs may suggest that the effects of lifestyle factors or cancer screening may outweigh the effects of occupational radiation exposure. The reduced ERR estimates when the analysis was conducted excluding adjustment for employment duration indicate a healthy worker survivor effect in this cohort. Thus, statistically not significant effects between cancer risk and occupational radiation exposure do not directly imply that there were no effects of radiation exposure among these groups. Data integration of this registry-linked cohort and previous survey data is in progress using multiple imputation techniques to obtain data on possible important confounders such as smoking status and alcohol consumption.

A few individual cancer sites including the thyroid and breast showed increased SIRs; however, none of the cancer sites showed positive ERRs. This pattern of thyroid cancer was similar to that in the USRT, showing significantly increased SIRs ${ }^{31}$ and no significant increased ERRs. ${ }^{32}$ Previous studies showed that significant trends in the incidence of breast cancer were mainly limited to workers who were born before 1930 but less clear for more recent birth cohorts in the USRT ${ }^{33}$ or workers who first employed before to 1960 in Chinese medical workers. ${ }^{34}$ These findings may suggest that the increased SIRs of thyroid and female breast cancer risks were due to the high accessibility to cancer screening among medical radiation workers. The finding of increased SIRs from prostate and kidney cancer in male workers and from brain cancer in female workers, but no increase in ERRs, may also be related to overdiagnosis. ${ }^{35}$ Our non-significant association of leukaemia with occupational radiation dose was consistent with the findings of studies on Norwegian nurses ${ }^{36}$ and a USRT study ${ }^{37}$ but inconsistent with the increase observed among medical radiation workers in Canada, ${ }^{25}$ Japan $^{38}$ and China. ${ }^{39}$ However, the ERR findings from individual cancer sites should be interpreted with caution due to the low cumulative doses and narrow radiation dose ranges.
The strengths of this study include the use of individual dosimetry data for organ dose estimation, linkage to the comprehensive national cancer incidence registry data, and inclusion of all monitored diagnostic medical radiation workers in South Korea. However, the relatively short follow-up period, low cumulative dose, and lack of lifestyle factors are important limitations. In addition, there were uncertainties regarding the estimation of organ doses, such as the validity of the badge dose, assumptions of irradiation geometry, photon energy from radiationproducing machines and attenuation due to the use of a lead apron. The idea of collaborative project to pool existing cohorts of medical radiation workers ${ }^{5}$ could have benefit to minimise the limitations by covering the wide variation of dose ranges and including early period and current workers.

In summary, our study provides cancer incidence in South Korean diagnostic medical radiation workers and showed nonsignificant positive cancer risks associated with occupational radiation exposure. The findings were generally comparable to those seen in other occupational radiation exposure studies and added some knowledge about cancer risk from a recently constructed cohort of medical radiation workers. However, because the majority of the workers were young and had a relatively short time since the first exposure, which is rapidly growing with the development of techniques for radiation exposure, further follow-up will improve the precision of the risk and contribute to better understand the effects of occupational radiation exposure on cancer incidence.

Contributors WIL conceptualised the research and wrote the first draft of the manuscript. YC and YJB estimated radiation organ dose. WJL and SK performed the data analyses. DLP, SK, YJB, S-AC and YC provided advice on the data analyses and critically revised the manuscript. All authors contributed to the draft revision and approved the final manuscript.

Funding This work was supported by the National Research Foundation of Korea (NRF) grant funded by the Korea government (MSIT) (No. 2020R1A2C1008891). The funding body had no role in the design of the study, data collection, analysis, interpretation or writing the manuscript.

Competing interests None declared.

Patient consent for publication Not required.

Ethics approval This study was reviewed and approved by the Institutional Review Board of Korea University (KUIRB-2019-0092-04).

Provenance and peer review Not commissioned; externally peer reviewed. Data availability statement No data are available.

Supplemental material This content has been supplied by the author(s). It has not been vetted by BMJ Publishing Group Limited (BMJ) and may not have been peer-reviewed. Any opinions or recommendations discussed are solely those of the author(s) and are not endorsed by BMJ. BMJ disclaims all liability and responsibility arising from any reliance placed on the content. Where the content includes any translated material, BMJ does not warrant the accuracy and reliability of the translations (including but not limited to local regulations, clinical guidelines, terminology, drug names and drug dosages), and 
is not responsible for any error and/or omissions arising from translation and adaptation or otherwise.

Open access This is an open access article distributed in accordance with the Creative Commons Attribution Non Commercial (CC BY-NC 4.0) license, which permits others to distribute, remix, adapt, build upon this work non-commercially, and license their derivative works on different terms, provided the original work is properly cited, appropriate credit is given, any changes made indicated, and the use is non-commercial. See: http://creativecommons.org/licenses/by-nc/4.0/.

ORCID iD

Won Jin Lee http://orcid.org/0000-0002-0254-7267

\section{REFERENCES}

1 Wakeford R. Radiation in the workplace-a review of studies of the risks of occupational exposure to ionising radiation. J Radiol Prot 2009;29:A61-79.

2 Linet MS, Kim KP, Miller DL, et al. Historical review of occupational exposures and cancer risks in medical radiation workers. Radiat Res 2010;174:793-808.

3 United Nations Scientific Committee on the Effects of Atomic Radiation (UNSCEAR). Sources and effects of ionizing radiation. UNSCEAR 2008 report: volume I. Annex $B$ : exposures of the public and workers from various sources of radiation. New York United Nations; 2010.

4 Yoshinaga S, Mabuchi K, Sigurdson AJ, et al. Cancer risks among radiologists and radiologic technologists: review of epidemiologic studies. Radiology 2004;233:313-21.

5 Chartier H, Fassier P, Leuraud K, et al. Occupational low-dose irradiation and cancer risk among medical radiation workers. Occup Med 2020;70:476-84.

6 Choi Y, Shil Cha E, Jin Bang Y, et al. Estimation of organ doses among diagnostic medical radiation workers in South Korea. Radiat Prot Dosimetry 2018;179:142-50.

7 Lee WJ, Ko S, Bang YJ, et al. Mortality among diagnostic medical radiation workers in South Korea, 1996-2015. Occup Environ Med 2018;75:739-41.

8 Lee WJ, Preston DL, Cha ES, et al. Thyroid cancer risks among medical radiation workers in South Korea, 1996-2015. Environ Health 2019;18:19.

9 Cha ES, Zablotska LB, Bang YJ, et al. Occupational radiation exposure and morbidity of circulatory disease among diagnostic medical radiation workers in South Korea. Occup Environ Med 2020;77:752-60.

10 Lee WJ, Cha ES, Bang YJ, et al. Suicide deaths among diagnostic medical radiation workers in South Korea, 1996-2017. Occup Environ Med 2020;77:675-80.

11 Lee WJ, Choi Y, Ko S, et al. Projected lifetime cancer risks from occupational radiation exposure among diagnostic medical radiation workers in South Korea. BMC Cancer 2018;18:1206.

12 Hong S, Won YJ, Park YR. Cancer statistics in Korea: incidence, mortality, survival, and prevalence in 2017. Community of population-based regional cancer registries. Cancer Res Treat 2020;52:335-50.

13 WHO. International statistical classification of diseases and related health problems. 10th revision. Geneva WHO; 1992.

14 International Agency for Research on Cancer. Radiation [IARC monographs on the evaluation of the carcinogenic risks to humans. Volume 100D. Lyon: IARC publication, 2012.

15 Zablotska LB, Bazyka D, Lubin JH, et al. Radiation and the risk of chronic lymphocytic and other leukemias among chornobyl cleanup workers. Environ Health Perspect 2013;121:59-65.

16 Oh C-M, Cho H, Won Y-J, et al. Nationwide trends in the incidence of melanoma and non-melanoma skin cancers from 1999 to 2014 in South Korea. Cancer Res Treat 2018;50:729-37.

17 Park S, Oh C-M, Cho H, et al. Association between screening and the thyroid cancer "epidemic" in South Korea: evidence from a nationwide study. BMJ 2016;355:i5745.
18 Korean Ministry of Food and Drug Safety. Occupational radiation exposure and health effects in a cohort of diagnostic radiation workers in Korea. Osong Korean Ministry of Food and Drug Safety; 2013.

19 Petoussi-Henss N, Bolch WE, Eckerman KF, et al. ICRP Publication 116. Conversion coefficients for radiological protection quantities for external radiation exposures. Ann ICRP 2010:40:1-257.

20 International Commission on Radiological Protection (ICRP). ICRP Publication 74. Conversion coefficients for use in radiological protection against external radiation. Ann ICRP 1996;26:1-205.

21 Simon SL, Weinstock RM, Doody MM, et al. Estimating historical radiation doses to a cohort of U.S. radiologic technologists. Radiat Res 2006;166:174-92.

22 Sun Z, Inskip PD, Wang J, et al. Solid cancer incidence among Chinese medical diagnostic X-ray workers, 1950-1995: estimation of radiation-related risks. Int J Cancer 2016;138:2875-83.

23 National Research Council (NRC). Health risks from exposure to low levels of ionizing radiation: BEIR VII phase 2. New York: National Academies Press, 2006.

24 Berrington de Gonzalez A, Daniels RD, Cardis E, et al. Epidemiological studies of lowdose ionizing radiation and cancer: rationale and framework for the monograph and overview of eligible studies. J Natl Cancer Inst Monogr 2020;2020:97-113.

25 Sont WN, Zielinski JM, Ashmore JP, et al. First analysis of cancer incidence and occupational radiation exposure based on the National dose registry of Canada. Am J Epidemiol 2001;153:309-18.

26 Rajaraman P, Doody MM, Yu CL, et al. Cancer risks in U.S. radiologic technologists working with fluoroscopically guided interventional procedures, 1994-2008. AJR Am J Roentgenol 2016;206:1101-9.

27 Kitahara CM, Linet MS, Drozdovitch V, et al. Cancer and circulatory disease risks in US radiologic technologists associated with performing procedures involving radionuclides. Occup Environ Med 2015;72:770-6.

28 Linet MS, Kitahara CM, Ntowe E, et al. Mortality in U.S. physicians likely to perform fluoroscopy-guided interventional procedures compared with psychiatrists, 1979 to 2008. Radiology 2017;284:482-94

29 Berrington de González A, Ntowe E, Kitahara CM, et al. Long-Term mortality in 43763 U.S. radiologists compared with 64990 U.S. psychiatrists. Radiology 2016;281:847-57.

30 Ko S, Kang S, Ha M, et al. Health Effects from Occupational Radiation Exposure among Fluoroscopy-Guided Interventional Medical Workers: A Systematic Review. J Vasc Interv Radiol 2018;29:353-66.

31 Sigurdson AJ, Doody MM, Rao RS, et al. Cancer incidence in the US radiologic technologists health study, 1983-1998. Cancer 2003;97:3080-9.

32 Kitahara CM, Preston DL, Neta G, et al. Occupational radiation exposure and thyroid cancer incidence in a cohort of U.S. radiologic technologists, 1983-2013. Int J Cancer 2018;143:2145-9.

33 Preston DL, Kitahara CM, Freedman DM, et al. Breast cancer risk and protracted lowto-moderate dose occupational radiation exposure in the US radiologic technologists cohort, 1983-2008. Br J Cancer 2016;115:1105-12.

34 Wang JX, Boice JD, Li BX, et al. Cancer among medical diagnostic X-ray workers in China. J Natl Cancer Inst 1988;80:344-50.

35 Welch HG, Black WC. Overdiagnosis in cancer. J Natl Cancer Inst 2010;102:605-13.

36 Lie J-AS, Kjaerheim K, Tynes T. Ionizing radiation exposure and cancer risk among Norwegian nurses. Eur J Cancer Prev 2008;17:369-75.

37 Linet MS, Little MP, Kitahara CM, et al. Occupational radiation and haematopoietic malignancy mortality in the retrospective cohort study of US radiologic technologists, 1983-2012. Occup Environ Med 2020;77:822-31.

38 Yoshinaga S, Aoyama T, Yoshimoto Y, et al. Cancer mortality among radiological technologists in Japan: updated analysis of follow-up data from 1969 to 1993. J Epidemiol 1999;9:61-72.

39 Wang JX, Zhang LA, Li BX, et al. Cancer incidence and risk estimation among medical X-ray workers in China, 1950-1995. Health Phys 2002;82:455-66. 